\title{
Socio-Economic Issues among Felda Settlers in Perlis
}

\author{
Bahijah Md Hashim \\ Faculty of Business Management, Universiti Teknologi MARA \\ 02600, Arau, Perlis, MALAYSIA
}

Tel: 60-4-988-2747 E-mail: bahijah@perlis.uitm.edu.my

Adilah Abdul Hamid

Faculty of Business Management, Universiti Teknologi MARA

02600, Arau, Perlis, MALAYSIA

Tel: 60-4-986-1001Ｅ-mail: adilah@perlis.uitm.edu.my

Mat Saad Abdullah

Faculty of Business Management, Universiti Teknologi MARA

02600, Arau, Perlis, MALAYSIA

Tel: 60-4-988-2000

Rohana Alias

Department of Science, Mathematics and Statistics, Universiti Teknologi MARA

02600, Arau, Perlis, MALAYSIA

Tel: 60-4-9888-2000

Sarina, Muhamad Noor (Corresponding author)

Faculty of Business Management, Universiti Teknologi MARA

02600, Arau, Perlis, MALAYSIA

Tel: 60-4-988-2879 E-mail: smnoor95@yahoo.com

\begin{abstract}
After almost fifty years of operation, government through a number of announcements declared that FELDA (Federal Land Development) schemes need to be revitalized so that it could play its role more effectively as a vehicle that would accelerate the country's economic growth. Having raised this point, the major aim of this study is to examine the major socio-economic issues and the current socio-economic status of FELDA settlers.Information was gathered through face-to-face interview with the Mata Air FELDA settlers and the Rimba Mas FELDA settlers in Perlis. Descriptive statistics such as mean, standard deviation and percentages were employed to describe the socio-economic problems and issues studied. The findings of the study indicate the implication of the ageing phenomenon of the FELDA settlers in Perlis to some extent affect the settlers' ability to work effectively on their plantation. It is also found that the second generation issue has become the most significant factor contributing to the productivity and income increment of the FELDA settlers in Perlis as compared to other selected socio-economic variables. The result also suggested that, the
\end{abstract}


ageing phenomenon, second generation issue and entrepreneurship problem must be seriously taken into consideration in order to accelerate the FELDA's growth specifically and the country's growth generally.

Keywords: Socio-economic issues, FELDA settlers, FELDA schemes, Rejuvenated FELDA schemes, Economic growth

\section{Introduction}

Rejuvenated FELDA schemes? Yes, FELDA schemes (and hence FELDA community) will be reengineered; they will be modernized; they will be rejuvenated to become 'new' land development and settlement schemes. After nearly two decades they have been neglected, the government announced that development revolution would be brought to FELDA schemes. Today, after five decades of its creation and operations, FELDA's image is not just as a Government agency responsible for large scale land development and settlement schemes but it has also ventured into manufacturing and commercial activities.

The activities and achievements of FELDA during the first two decades of its foundation are detailed in Tengku Shamsul Baharin et al. (1977). FELDA also has instituted further changes and expanded into new directions during its third decade, and these are examined by Tengku Shamsul Baharin et al. (1988). Fee (1976) has the view that FELDA was established in 1956 in respond to the priority given to land development for the Malay smallholder settlement and the failure of a Government agency known as RIDA (Rural Industrial Development Authority). It was established to undertake large scale land development and settlement. As Perumal (1991) puts it, conceptually, the FELDA program aims at bringing together techno-economic strengths of the plantation sector and the socio-economic needs of the smallholding sector. Practically, this concept takes the form of clearing virgin jungle, establishing economically viable crops, providing a settlement area with a comprehensive range of infrastructure, and the emplacement of economically handicapped rural families to participate in the package of activities so created.

According to Tengku Shamsul Baharin et al. (1977: 55), "The settlers are the nucleus of FELDA land development and settlement program. They become not only the reason for development but also the means of development." Actually, in recent years, the success story of FELDA schemes has been questioned. Several issues concerning FELDA schemes have been raised in the literature. In his study, Fee (1976) identified two major issues facing FELDA settlers. First, there are second generation unemployment as the settlers' dependents enter the labor market and secondly, the problem of unequal distribution of income among settlers from different types of FELDA schemes.

In recent years, the socio-economic problems faced by FELDA schemes are numerous. Some of the intriguing ones are as follows:

a) Relative poverty. If some twenty or thirty years ago FELDA was lauded for being successful in transferring the landless and poor farmers from their 'vicious cycle of poverty' into modern settlements of FELDA schemes, today FELDA settlers are claimed to be relatively poor. FELDA settlers are believed not to have enjoyed much improvement in their income levels and quality of life as compared to their counterparts in the secondary or the tertiary sector of the national economy. Depending on the movements in the prices of oil palm or rubber, the income of FELDA settlers has been unstable through time.

b) Ageing phenomenon. It has been nearly fifty years since the first FELDA scheme was implemented. Today it is believed that the majority of the first generation of FELDA settlers has been above fifty years old. This ageing phenomenon is believed, to some extent, to have affected settlers' ability work and hence, productivity. Are their children interested enough to replace them working on their plantations?

c) Farmer-manager phenomenon: That is, settlers as farmers, act as managers: They just manage their plantations; they just depend on paid workers - most of them are foreign workers - to work on their plantations. This phenomenon could perhaps be attributed to a number of factors: First, ageing problem. Second, the sizes of their plantations are too large for them to work alone (that is, in the case of rubber schemes, they cannot finish tapping their rubber threes within a day if they work alone). Thirdly, complacent attitude: That is, since their standard of living as settlers has become much better as compared to the situation before joining FELDA, then they do not feel any pressure to work harder. Lastly,easy to get cheap workers.

We believe that this farmer-manager phenomenon is a challenging issue for FELDA authority because one of the strategies followed by FELDA in developing its schemes was to provide economic size piece of land (plantation) for each family. Through time, has this 'economic size 'become'diseconomy of size plot of land? Another related issue is that most foreign workers have no experience in tapping rubber and thus they might cause damage to the rubber threes.

d) Land underutilization and badly managed settlement areas: If one visits any FELDA settlement area, we believe that he (she) would find plenty of areas which are filled with bushes. Plots of land which are meat for fruit production or for planting vegetables are left idle. FELDA settlement areas today do not appear to attractive and beautiful. Indeed, 
their kampungs are similar to any traditional Malay kampung outside FELDA schemes. Is this then, a reflection of FELDA's failure in creating modern and well-organized settlement areas which could be proud of?

e) Land ownership issue: To some extent land ownership still appears to be an unsettled issue among settlers (Nurwati Badarulzaman \& Fatimah Hassan, 2005).

In closing, the issues pertaining to FELDA schemes discussed appear to be challenging problems for the FELDA authority and the Government as well. Correspondingly, if we were to see the Government's move to revitalize FELDA schemes to be a successful one, then these issues need to be properly and seriously addressed and managed. Due to the above scenario, the researchers planned to meet the following objectives:

1. To closely (and critically) examine the current socio-economic status of settlers in Perlis.

2. To identify some socio-economic issues and examine the roots behind the issues.

3. To come up with some recommendations that could be benefited by FELDA management in managing the issues.

\section{Methods}

To meet the purpose of the study, information was gathered through face-to-face interview and recorded in the prepared questionnaire. The total number of settlers in the Mata Air FELDA Scheme and the Rimba Mas FELDA Scheme is 249 and 161 respectively. Since the population size was quite small, the researchers have decided that our data collection should be based on a census rather than sampling. Accordingly, the total number of respondents in this study was 410 settlers.

Our data collection process was implemented in three stages: First, the collection of general information pertaining to the two FELDA schemes (and their settlers), involving a series of discussions with FELDA managers. This was followed by a pilot study though interviews with ten settlers using a structured questionnaire. The feedbacks from these interviews provided us insights into refining and improving our questionnaire. Our experience from this pilot study has then led us into a decision that the appropriate method in gathering the required information from the settlers would be face-to-face interview. Thus, the role of the questionnaire designed was to facilitate the questioning and recording process of the interview.

The questionnaire was designed in such a way to enable us to gather, inter alia, the following information:

(i) Basic personal information of settlers. This personal information section aims at gathering background information of settlers such as age, marital status, levels of education, occupation and income before joining FELDA scheme, number of household (family size) and even number of wives.

(ii) Information on the dependency of children. The purpose of this section was to collect information pertaining to 'population pressure' and the nature of future generation of 'settlers'. Among the questions posed were: the number of (schooling) children and levels of their study, number of children that cannot further their study (at least) to upper secondary level, number of children who are working (outside FELDA scheme), number of children who are interested to become settlers (farmers?).

(iii) Information on rubber production and income. In this section, our interests are, among others, in knowing settlers' weekly income as well as their net income, their tapping activities and types of rubber produced, and the issue of selling rubber (scrap) to 'outside' buyers (rather than to FELDA agency).

(iv) Information on working spirit and interest in entrepreneurship. While lately the Government has shown its interest the aspiration to turn (some?) of the settlers into entrepreneurs, are settlers really interested in this issue? Are there settlers in Perlis that are interested and have really participated in entrepreneurship activities? How about their attitude and interest towards their 'original' occupation as FELDA farmers? Do they themselves manage their plantation? How many hours daily do they spend working in their plantation? Have they 'fully' utilized the land that they have, for instance, for planting fruit threes, vegetables and/or other agricultural activities? How about their economic activities outside FELDA scheme and (side) income from these activities? It is hoped that answers to these questions could be provided through the present survey research.

(v) General socio-economic information. Among the information sought from settlers was the type and value of dwelling, other assets, their ownership status of FELDA land, the participation of settlers in organizational activities and other (non farming) activities. Lastly, settlers were asked about their views concerning the FELDA management (for each scheme); they were also asked to contribute their ideas on how to improve the management and welfare of settlers for each FELDA scheme under study.

This study was descriptive in nature. Being a descriptive study, the data was analyzed from the perspectives of descriptive statistics. Accordingly, statistical measures such as mean, standard deviation and percentages were employed to describe the socio-economic facts and phenomena studied. 
Notwithstanding the simplicity of the present study, we believe that it could provide some useful information on the current socio-economic status of FELDA settlers in Perlis. Given the uniqueness of FELDA schemes in Perlis in terms of its geographical location as well as climatic elements (and the related socio-cultural phenomena), it is hoped that findings of the study could provide some insights for the FELDA authority and management in planning program, approaches and strategies towards the successfully rejuvenated FELDA schemes in Perlis.

\section{Results and Discussion}

The results were derived by examining and identifying basic demographic features and socio-economic background of settlers. The variables of our interest in this case were age, level of education, number of household, number of wife, number of children, state of origin, job before joining FELDA scheme, previous monthly income and year joining FELDA scheme. Attempts were also made to identify settlers' actual reason(s) for joining FELDA scheme and hence, to some extent, their attitude towards life as settlers.

In terms of demographic profile as given in Table 1, the mean ages of the settlers were 51.1 years with a standard deviation of 5.4 and majority of them had only elementary school education. The mean number of household was 5.39 with a standard deviation of 1.9 .

\section{Insert Table 1 here}

This finding is consistent with the finding of the previous researchers. The implication of this is that of the ageing phenomenon and the second generation issue which to some extent has affected the settlers' ability to work effectively on their plantation and hence affecting their productivity.

Before joining FELDA the settlers had a mean monthly income of RM425.71 with a standard deviation of RM397.45. About $50 \%$ of the settlers had monthly income of less than RM350.00 per month which is well below the poverty line. The study has found that their mean monthly income as settlers is RM1373.28 with standard deviation of RM711.12 (Refer to Table 2). The mean and standard deviation monthly income of FELDA Mata Air and FELDA Rimba Mas settlers is RM1563.11 and RM1244.27 with standard deviation of RM 830.94 and RM584.17 respectively.

\section{Insert Table 2 here}

However this reported figure does not tally with mean monthly income recorded by the FELDA management of both schemes. Further investigation revealed that the settlers did not include deductions on loan settlement made by the managements as part of their income.

Another unique finding from the study is that nearly $50 \%$ of the respondents were found to have part time jobs such as taxi driving, paddy farming, small trading and working as laborers. This is especially so during the 'rest season' or drought seasons for the months of January, February and March each year. During this time latex production is relatively very low while the production of 'scrap rubber' is almost that of the normal season as highlighted in the previous findings. The facts that scrap rubber production relatively stable through the year have indicated that it is a popular source of income for the settlers.

The farmer-manager phenomenon secured to be an issue in the study. Some of the settlers managed their farm by depending on paid workers. The size of the plantation which is too large for the settlers to work alone coupled with the old age has led to the farmer-manager phenomenon. This again has the implication on productivity.

Apart from the farmer-manager phenomenon, dependency issue has also been explored. The mean number of children per settler family is $4.39 \%$.

The study revealed that majority of the settlers has children either in the primary school or secondary school while only $12.7 \%$ has children studying at institutions of higher learning. Some of the elder children are working in the government and private sectors with only $1.4 \%$ of them work as professionals. However a very worrying trend is that most of the settler's children were NOT interested to work on the FELDA Land schemes. Most of them prefer to seek employment elsewhere. If this trend persists the future of FELDA scheme looks bleak unless remedial measures are taken to ensure they stay on not just as farmer settlers. The study has found that most of the settlers are living in renovated houses. However the cost of renovation is rather moderate with a mean of RM17211 and standard deviation of RM16383.67.

Ownership of other assets show that only $8 \%$ of the respondents owned computers. As for car ownership, majority of the settlers has cars with value less than RM20000 with a mean value of RM12107.61.

Motorcycle ownership is very important in the FELDA settlement with 70\% of the settlers owning motorcycles. The mean value of motorcycle is RM3393.44 with a standard deviation of RM2425.46. A summary of value of assets worth by the settlers excluding their house showed a mean of RM10161.12 with a standard deviation of RM15529.82.

Realizing that the settlers cannot rely on agriculture alone for sustainable income and improvement in their standard of living, the government has introduced the SAWARI programmed to induce the settlers to be involved in entrepreneurial 
activities. However, only $48 \%$ of the settlers were aware of such programs while a small minority of $6 \%$ was involved in various activities like sewing and handicraft. Obviously there is a big gap between awareness and involvement in the SAWARI programmed.

Another issue relating to awareness is that of the loan benefits available to the settlers. Although there are many credit facilities as highlighted in the findings there is still a big gap between awareness and participating in the loan schemes for their social and economic development.

\section{Conclusions}

The researchers have concluded that although there has been a significant increase in the income of the settlers, this income increment is still relatively small compared to their counterparts in the other modern sectors.

It is recommended that FELDA settlers in Perlis cultivate the cashew plant and on the vacant plot meant for the orchards near their home on a commercial basis. The cashew plant is recommended based on several reasons namely, the low cost of production and the low management cost.

Another plant recommended is the jungle bamboo plant a group of woody perennial evergreen plants. The bamboo plant has a high economic and cultural significance in Asia where they are used extensively in gardens as building materials and a food source. Considering bamboo plant is a multipurpose plant providing timber, food, medicinal and industrial products, it is recommended as a commercial cash crop in the FELDA schemes.

The next recommended plant is Jatropha Curcas. The plant produces many useful products especially the seed from the oil can be abstracted and used in the place of the kerosene and diesel as a substitute for fuel wood and for the soap making. More research is required before the potential of Jatropha Curcas in the biodiesel industry can be realized.

Lastly, the researchers recommended that the government should develop more Felda entrepreneurs among the settlers and should play more dominant role as production and marketing agents. For instance, the government can help the settlers by encouraging them to involve in some of the entrepreneurial activities and upgrading the present entrepreneurs through constant training and counseling.

\section{References}

Fee Wan Leong. (1976). Land Resource Utilization and Land Use Controls in West Malaysia 1957. Umi Dissertation, University of Wisconsin Madison, PhD 1976

Kwong Yuan, Chong. (1983). "Niaga dan Pembangunan Luar Bandar" (Trade and Rural Development), in H. Osman-Rani and E. K. Fisk (ed.), Ekonomi Politik Malaysia (Political Economy of Malaysia). Petaling Jaya: Fajar Bakti Sdn. Bhd.

Nurwati Badarulzaman \& Fatimah Hassan. (2005). FELDAJAYA as sustainable city for Felda: Will it work? An exploratory study. 8 International Asian Planning Schools Association Congress (APSA 2005). Grand Plaza Park Royal Hotel, Penang.

Perumal, S. (1991). FELDA's Experience in Rural Development in Mohd Yaakub Johari (ed.), Issues and Strategies in Rural Development, Kota Kinabalu: Institute for Development Studies (Sabah).

Tengku Shamsul Baharin \& Thong Hong, Lee Boon. (1988). FELDA: Three Decades of Evolution. Kuala Lumpur: Felda Publication.

Tengku Shamsul Baharin, P.D.A Preira \& Lim Heng Kow. (1977). FELDA 21 Years of Land Development. Kuala Lumpur: FELDA Publication.

Table 1. Demographic profile

\begin{tabular}{lll}
\hline & Mean & Standard deviation \\
\cline { 2 - 3 } Age (years) & 51.1 & 5.4 \\
Number of household & 5.39 & 1.9 \\
\hline
\end{tabular}

Table 2. Monthly income of settlers

\begin{tabular}{lll}
\hline & Before joining FELDA & After joining FELDA \\
\cline { 2 - 3 } Mean & 425.71 & 1373.28 \\
Standard deviation & 397.45 & 711.12 \\
\hline
\end{tabular}

